\title{
Regulation of histone arginine methylation/demethylation by methylase and demethylase (Review)
}

\author{
JING ZHANG ${ }^{1,2}$, LI JING ${ }^{1}$, MENGHAN LI ${ }^{1}$, LINGFENG HE $^{1}$ and ZHIGANG GUO ${ }^{1}$ \\ ${ }^{1}$ Jiangsu Key Laboratory for Molecular and Medical Biotechnology, College of Life Sciences, \\ Nanjing Normal University, Nanjing, Jiangsu 210097, P.R. China; ${ }^{2}$ Laboratory of Molecular Gerontology, \\ National Institute on Aging, National Institutes of Health, Baltimore, MD 21224, USA
}

Received September 28, 2018; Accepted March 6, 2019

DOI: $10.3892 / \mathrm{mmr} .2019 .10111$

\begin{abstract}
Histone arginine methylation is a universal post-translational modification that has been implicated in multiple cellular and sub-cellular processes, including pre-mRNA splicing, DNA damage signaling, mRNA translation, cell signaling and cell death. Despite these important roles, the understanding of its regulation with respect to certain other modifications, such as phosphorylation and acetylation, is very poor. Thus far, few histone arginine demethylases have been identified in mammalian cells, compared with nine protein arginine methyltransferases (PRMTs) that have been reported. Studies have reported that aberrant histone arginine methylation is strongly associated with carcinogenesis and metastasis. This increases the requirement for understanding the regulation of histone arginine demethylation. The present review summarizes the published studies and provides further insights into histone arginine methylases and demethylases.
\end{abstract}

\section{Contents}

1. Introduction

2. Arginine methylases

3. Arginine demethylases

4. Conclusions and future perspectives

\section{Introduction}

Post-translational modifications of histone proteins serve key roles in eukaryotic cellular processes, including acetylation,

Correspondence to: Professor Zhigang Guo, Jiangsu Key Laboratory for Molecular and Medical Biotechnology, College of Life Sciences, Nanjing Normal University, 1 Wenyuan Road, Nanjing, Jiangsu 210097, P.R. China

E-mail: guozgang@gmail.com

Key words: post-translational modification, histone arginine methylase, histone arginine demethylase, JumonjiC protein methylation, phosphorylation and ubiquitination. As epigenetic markers, these modifications provide perspectives on DNA repair, signal transduction, transcriptional regulation, chromatin remodeling and the modulation of protein interactions (1). Enzymes that deposit and remove modifications have been regarded as important drug targets and have been developed to treat various diseases, including cancer. The reversible processes involved in these pathways are mediated by histone methyltransferases and histone demethylases. Modifications of N-terminal tail histones include acetylation, ubiquitination, phosphorylation and methylation of lysine and arginine residues (2), all of which have been addressed in studies involving specific enzymes, including the acetyltransferases, arginine and lysine methyltransferases, ubiquitin ligases and kinases responsible for these modifications. For example, numerous histones have been demonstrated to contain methylarginines (3). Arginine methylation may readily modulate the structure of arginine residues and binding interactions with other proteins, which regulate physiological functions. As abnormal histone arginine methylation is a common phenotype in tumorigenesis, studies of histone arginine methylated substrates associated with cancer are presented in Table I (4-9). Differential methylation modification in histones may either activate or repress gene transcription, depending on the location and nature of these modifications (10). Three distinct types of methylated arginine residues have been reported in eukaryotes. The most prevalent is asymmetric $\omega-\mathrm{NG}, \mathrm{N}^{\mathrm{G}}$-dimethylarginine (ADMA), in which two methyl groups are replaced on one of the terminal nitrogen atoms of the guanidine group (11). Other derivatives include $\omega-\mathrm{N}^{\mathrm{G}}$-monomethylarginine (MMA) and $\omega-\mathrm{NG}$, NG-dimethylarginine (SDMA).

The discovery of two enzymes, deaminase enzymes peptidyl arginine deaminase 4 (PAD4) and Jumonji domain-containing protein 6 (JMJD6) changed the consensus of opinion regarding the reversibility of methylation. PAD4 is able to catalyze the demethylation reaction and convert arginine residues into citrulline. JMJD6, an Fe (II)- and 2OG-dependent JumonjiC (JmjC)-domain-containing oxygenase that is also able to catalyze arginine demethylation, was identified as an arginine demethylase. These demethylation techniques have recently led to work by the authors of the present study, focusing on arginine demethylation. 
In the present review, the current perspective on arginine methylases/demethylases, including the controversy around JMJD6, in addition to the novel demethylation activity of $2 \mathrm{OG}$ oxygenase family histone lysine demethylases is summarized. Although few arginine demethylases have been identified, any dynamic posttranslational modification mechanism is likely to be involved in carcinogenesis and metastasis, which makes them an important field of study.

\section{Arginine methylases}

Arginine residues may be differentially methylated by different types of protein arginine N-methyltransferases (PRMTs) (12), which are classified as type I, II, III or IV enzymes (Fig. 1). Type I and II enzymes regulate gene transcription via methylation of histone proteins. Type I PRMTs (PRMT1, PRMT3, PRMT4 and PRMT6) catalyze ADMA on H3R2 and H4R3, leading to transcriptional activation and ribosomal biosynthesis $(13,14)$. PRMT1 is the principal methyltransferase in human cells, modifying $\sim 90 \%$ of methylated arginine residues. PRMT1 generally recognizes arginines within a glycine-arginine-rich region, a motif present in numerous RNA- or DNA-binding proteins (15). PRMT1 is overexpressed in various human cancer types, triggering aberrant hypermethylation of its substrates involved in tumorigenesis. Type II PRMTs (PRMT5 and PRMT7) cause the formation of SDMA on H3R8 and H4R3, resulting in transcriptional repression $(16,17)$. In addition, these enzymes may also regulate other cellular activities by methylating non-histone proteins. In total, $>100$ non-histone proteins have been reported to contain methylated arginine sites (18). MRE11, p53 and DNA polymerase $\beta$, which are associated with DNA replication and DNA damage repair, are reported to be regulated by arginine methylation (11). Most recently, stress granules (SGs) which are cytoplasmic condensates of stalled messenger ribonucleoprotein complexes, have been associated with rapid demethylation on Ras-GAP SH3-binding protein 1 (G3BP1) under stress conditions (19). Type III and type IV PRMTs only catalyze monomethylation. In addition, type IV PRMT has only been identified in yeast (20).

The function of PRMT is associated with multiple cellular activities, including proliferation, transformation and anti-apoptotic processes, all of which are involved in tumorigenesis. PRMT activity may be influenced by expression regulation, PRMT macromolecule formation, substrate accessibility, other forms of posttranslational modification and protein-protein interactions. Alteration of PRMT expression and dysregulation of their enzymatic activity, principally upregulation, has been observed in early embryonic lethality in mice and a number of human cancer types, as described in Table II (8,21-44). PRMT1 is an important methyltransferase with a wide substrate spectrum (15). PRMT5 is critical for the maintenance of pluripotency in mouse embryonic stem cells, as a key suppressor of gene differentiation (45). Due the critical role of PRMT1 and PRMT5, studies have revealed that deletion of PRMT1 or PRMT5 invariably causes embryonic lethality $(46,47)$. Other PRMTs are generally associated with development and aging, including PRMT2, PRMT3, PRMT6 and PRMT8. Mice with deficiencies in these PRMTs may be viable, but display a developmental delay following birth (48).
In summary, disruption of the balance in PRMTs triggering the aberrant methylation of proteins involved in cancer is implicated in promoting oncogenic transformation. Therefore, further investigation of the regulatory mechanisms, the use of model systems, and cellular biological discoveries are required to better understand the function of protein methylation in tumorigenesis.

\section{Arginine demethylases}

Family members, mechanism and investigation. Methylation at different residues can impact transcriptional and biological functions. Histone demethylase catalyzes the removal of methyl groups both on histone lysine and arginine residues. Histone lysine methylation, a process that was defined as a stable, irreversible chromatin marker, has now been established to be reversible by two families of lysine-specific histone demethylase (KDMs); one is the flavin-dependent KDM1, also termed LSD1, and the other is Fe (II)- and 2OG-dependent JmjC-domain-containing enzymes. The first histone demethylase identified was LSD1, which belongs to the superfamily of the flavin adenine dinucleotide-dependent amine oxidases (49). Subsequently, the first JmjC-containing histone demethylase, KDM2A, was identified (50). By sequence homology searching, two other members of the JmjC-containing histone demethylases were identified. All these observations made the system of methylation and demethylation of lysine a highly dynamic field of study.

As the reversible process of lysine methylation and demethylation has been better understood, the extent to which arginine methylation is dynamic is much less clear. Up to now, there have been no definite reports of specific arginine demethylases. While the arginine methylation may have biological relevance during gene expression and for the function of living organisms, well-balanced arginine methylation, in general, is required for mammalian development and is important for cellular proliferation and differentiation $(51,52)$. Aberrant modification patterns in proteins alter their activity and function, resulting in somatic diseases, including cancer (4-9). Consequently, certain enzymes (PRTMs for example) catalyze arginine methylation modifications, whereas other enzymes remove them. The dynamic cyclical process of methylation and demethylation of arginine reveals has revealed the existence of demethylases that reverse of arginine methylation (53). The existence and function of protein arginine methyltransferases have been known for over a decade (13). To date, two histone arginine demethylases have been identified: PAD4 and JMJD6 (54). PAD4 was deemed to be a demethylase that demethylates histones, converting monomethylated arginine to citrulline. JMJD6 directly converts methylarginine to arginine by removing the methyl group. Previous studies have provided significant insights into the mechanism and function of these demethylases, leaving much unresolved controversy (54). In a recent study, JMJD1B was reported to demethylate H4R3me2s and $\mathrm{H} 3 \mathrm{~K} 9 \mathrm{me} 2$ to facilitate gene expression for the development of hematopoietic stem and progenitor cells. JMJD1B, previously identified as a lysine demethylase for $\mathrm{H} 3 \mathrm{~K} 9 \mathrm{me} 2$, mediates the arginine demethylation of H4R3me2s and its intermediate, H4R3me1 (55). Histone lysine demethylases have also been 
Table I. Histone arginine methylated substrates associated with cancer.

\begin{tabular}{|c|c|c|c|}
\hline Author, year & Substrate & Function & Refs. \\
\hline Yang et al, 2010 & & TDRD3 binding & (4) \\
\hline Gao et al, 2006 & H4R3 & Transcriptional activation of ZEB1 (promotes EMT) & $(5)$ \\
\hline Pal et al, 2007 & & Represses expression of tumor suppressor genes (NM23) & $(6)$ \\
\hline Karkhanis et al, 2012 & & Regulates cellular response to DNA damage & $(7)$ \\
\hline Frietze et al, 2008 & H3R 17 & Transcriptional activation of E2F1 (promotes cell growth) & $(8)$ \\
\hline Pal et al, 2004 & H3R8 & Represses expression of tumor suppressor genes (ST7) & (9) \\
\hline Pal et al, 2004 & H2AR3 & Regulates cellular response to DNA damage & $(9)$ \\
\hline
\end{tabular}

TDTD3, tudor domain containing 3; ZEB1, zinc finger E-box binding homeobox 1; EMT, epithelial-mesenchymal transition.

\begin{tabular}{|l|l|l|l|l|l|l|}
\hline PRMTs & & & & & & Fomains \\
\hline PRMT1 & & & & & & \\
\hline
\end{tabular}

Figure 1. Overview of the human PRMT family. The catalytic methyltransferase domains contain a conserved binding domain (grey) with conserved motifs (black) that are important for the enzymatic reaction. Additional motifs: SH3 domain, zinc finger domain, myristoylation motif, FBox motif. PRMT, protein arginine methyltransferase.

reported to be associated with phenotypic plasticity and mammalian embryonic development $(56,57)$.

Mechanism and function of PAD4. PAD4 was previously identified to be associated with histone citrullination (58-60). The activity of the PAD enzymes is calcium $\left(\mathrm{Ca}^{2+}\right)$-dependent. Studies have reported that PAD4 is able to demethylate histones in vitro and in vivo by removing methyl groups from monomethylated arginine, thus regulating histone arginine methylation and gene expression. Modeling experiments suggest that asymmetrically and symmetrically dimethylated arginine cannot be accommodated in the active site of PAD4 due steric occlusion (61). PAD4 targets multiple sites in histones $\mathrm{H} 3$ and $\mathrm{H} 4$, including sites methylated by the coactivators histone-arginine methyltransferase CARM1 (H3R17) and PRMT1 (H4R3). By deaminating and demethylating histones, PAD4 is able to regulate endogenous pS2 gene expression stimulated by estradiol, and thereby affect chromatin structure and function. Demethylimination is not a 'true' demethylation reaction; it removes, but does not reverse methylation. Neutral citrulline is produced, which has considerably different chemical properties compared with unmethylated arginine, and this process is not sufficient to maintain arginine circulation $(62,63)$. In addition, as PAD4 is also able to catalyze non-methylated arginine, there is dispute as to whether PAD4 is a strict histone demethylase (64). The detailed mechanism of action of PAD4 is depicted in Fig. 2.

Mechanism and function of JMJD6. JMJD6 was previously described as a phosphatidylserine receptor of the plasma membrane of macrophages and dendritic cells (64). Chang et al (54) reported that JMJD6 functions as an arginine demethylase, which is an Fe (II)- and 2-oxoglutarate-dependent dioxygenase. The catalytic mechanism of JMJD6 is presented in Fig. 3. Like other JmjC domain-containing histone demethylases reported to be involved in histone lysine demethylation, JMJD6 shares extensive sequence and predicted structural homology with asparaginyl hydroxylase (54). Using conventional biochemical methods, it was reported that JMJD6 was able to demethylate H3R2me2 and H4R3me2 by removing methyl groups (54). Further studies demonstrated that JMJD6 demethylated R260 of estrogen receptor $\alpha$, thereby regulating estrogen 
Table II. Dysregulation of PRMTs and cancer.

\begin{tabular}{|c|c|c|c|}
\hline Author, year & PRMT & Effect of dysregulation in cancer & Refs. \\
\hline $\begin{array}{l}\text { Goulet et al, 2007, Zou et al, 2012, } \\
\text { Elakoum et al, 2008, Shia et al, 2012, } \\
\text { Mathioudaki et al, 2008, Mathioudaki et al, 2011, } \\
\text { Mathioudakis and Salvatori, } 2008\end{array}$ & PRMT1 & $\begin{array}{l}\text { Overexpressed in breast, prostate, } \\
\text { non-small cell lung, colon and } \\
\text { bladder cancer and leukemia }\end{array}$ & $(21-27)$ \\
\hline $\begin{array}{l}\text { Papadokostopoulou et al, 2009, } \\
\text { Zhong et al, 2012, Zhong et al, } 2011\end{array}$ & PRMT2 & $\begin{array}{l}\text { Overexpressed in breast cancer and } \\
\text { associated with ER } \alpha \text {-positive tumors }\end{array}$ & $(28-30)$ \\
\hline $\begin{array}{l}\text { Papadokostopoulou et al, 2009, } \\
\text { Takahashi et al, 2012, Singh et al, } 2004\end{array}$ & PRMT3 & $\begin{array}{l}\text { Higher levels of PRMT3 activity } \\
\text { in breast tumors }\end{array}$ & $(28,31,32)$ \\
\hline $\begin{array}{l}\text { Hong et al, 2004, Majumder et al, 2006, } \\
\text { Kim et al, 2010, Habashy et al, } 2013\end{array}$ & PRMT4 & $\begin{array}{l}\text { Overexpressed in breast, prostate and } \\
\text { colorectal cancer, non-small cell lung } \\
\text { carcinomas. Early expression in early } \\
\text { stages of hepatocarcinogenesis }\end{array}$ & $(33-36)$ \\
\hline $\begin{array}{l}\text { Pal et al, 2007, Wang et al, 2008, } \\
\text { Bao et al, 2013, Powers et al, } 2011\end{array}$ & PRMT5 & $\begin{array}{l}\text { Overexpressed in gastric, colorectal, } \\
\text { bladder, colon and lung cancer, } \\
\text { and lymphoma and leukemia }\end{array}$ & $(6,37-39)$ \\
\hline Yoshimatsu et al, 2011 & PRMT6 & $\begin{array}{l}\text { Overexpressed in bladder and lung } \\
\text { cancer cells. Downregulated in invasive } \\
\text { breast ductal carcinoma }\end{array}$ & $(40)$ \\
\hline $\begin{array}{l}\text { Thomassen et al, 2009, Yao et al, 2014, } \\
\text { Baldwin et al, } 2015\end{array}$ & PRMT7 & $\begin{array}{l}\text { Overexpressed in primary breast cancer } \\
\text { and breast cancer lymph node metastasis }\end{array}$ & $(41-43)$ \\
\hline Yang and Bedford, 2013 & PRMT8 & $\begin{array}{l}\text { Somatic mutations were found in ovarian, } \\
\text { skin and large intestine cancer }\end{array}$ & (44) \\
\hline
\end{tabular}

PRMT, protein arginine methyltransferase.

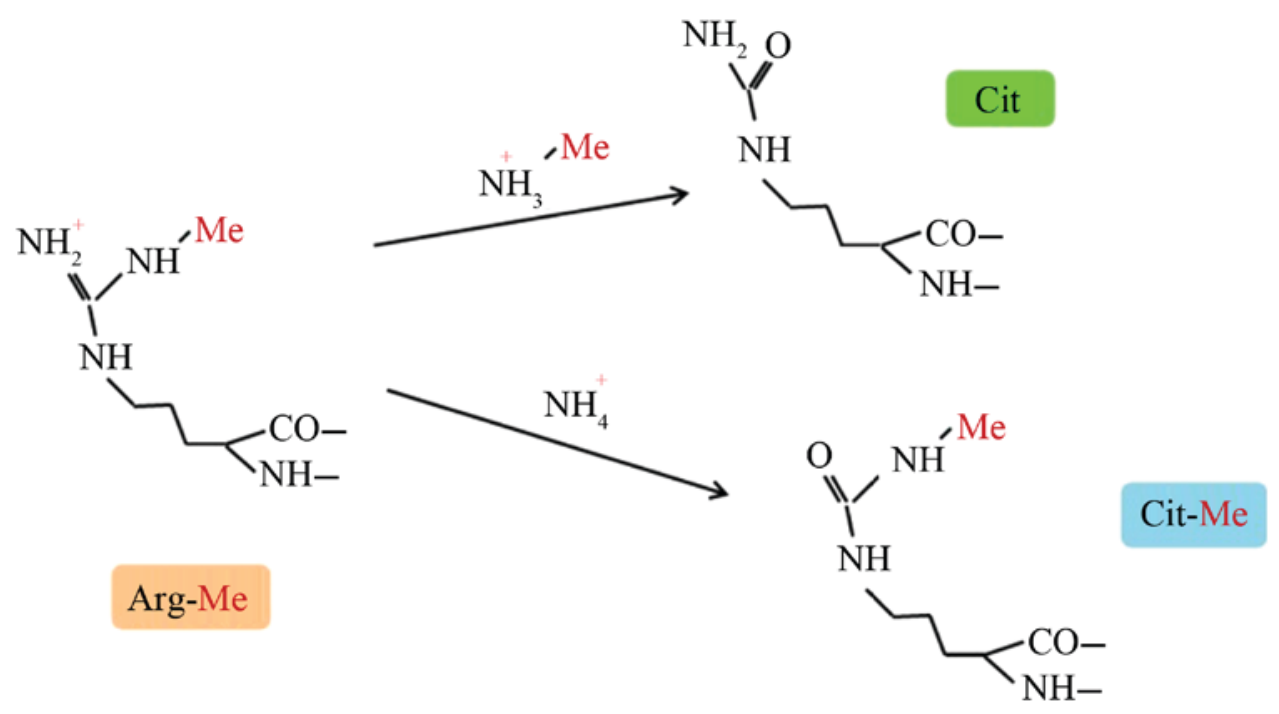

Figure 2. Mechanism and demethylase activity of PAD4. PAD4 demethylates H3 and H4. The two possible mechanisms of the PAD4 reaction with methylated arginine in a protein substrate are presented. PAD4, peptidyl arginine deaminase 4; Cit, citrulline.

nongenomic signaling (65,66). Previously, Lawrence et al (67) reported that JMJD6 was able to demethylate RNA helicase $A$ in cells infected with foot-and-mouth disease virus, which facilitates viral replication. Gao et al (68) observed that JMJD6 was able to demethylate the heat-shock $70 \mathrm{kDa}$ protein (HSP70) on the R469 residue in vitro. Factually, it was confirmed that the level of methylated HSP70 increased when JMJD6 was knocked down in cells, and the demethylation reaction following transfection with recombinant JMJD6 protein was assayed by mass spectrometry. More recent work reported that G3BP1 methylation was able to represses SG formation, and JMJD6 was demonstrated to interact with G3BP1 complexes and to function in G3BP1 demethylation to promote SG formation (69). Plant Jumonji homologs have also been reported to serve an essential 


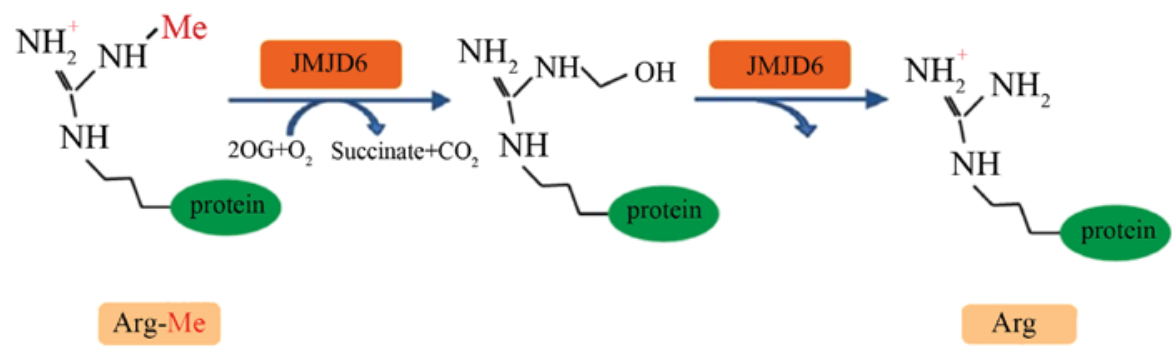

Figure 3. Mechanism and demethylase activity of JMJD6. The two demethylation steps catalyzed by JMJD6 are presented. Firstly, JMJD6 hydroxylates the methyl group consuming oxoglutarate (2OG), and a subsequent deformylation reaction produces formaldehyde $\left(\mathrm{CH}_{2} \mathrm{O}\right)$. JMJD6, Jumonji domain-containing protein 6.
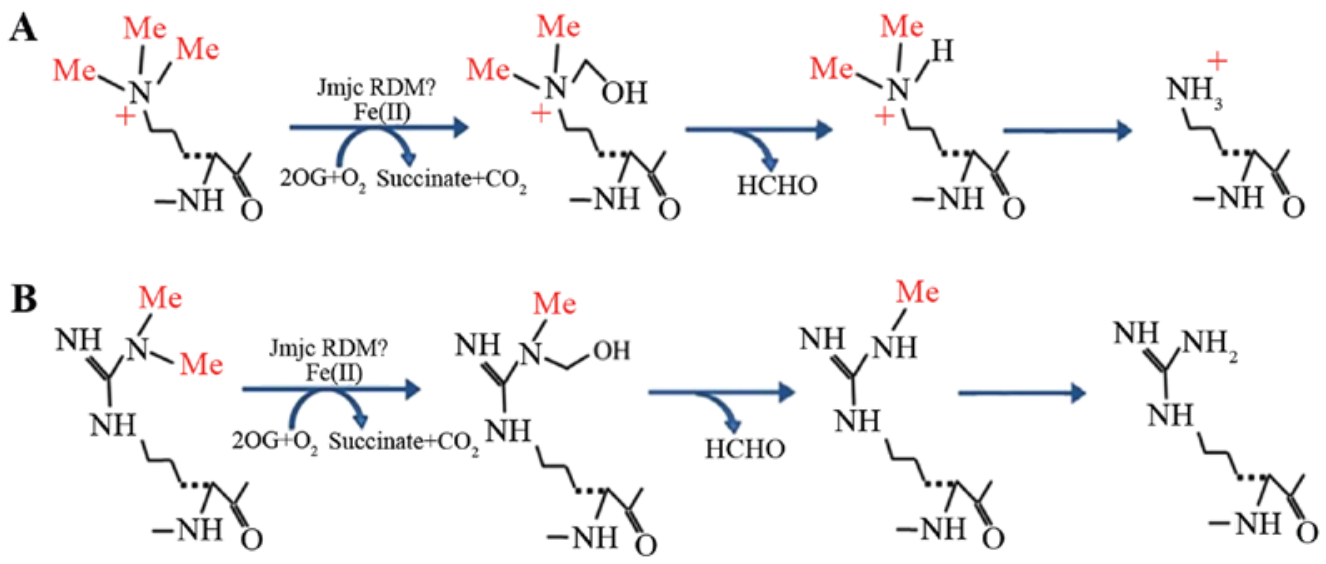

Figure 4. Demethylation mechanism of lysine and arginine. (A) Mechanism for JmjC-catalyzed lysine demethylation. JmjC lysine demethylases catalyze oxidative decarboxylation of $2 \mathrm{OG}$ to form succinate, carbon dioxide and a reactive iron(IV)-oxo intermediate. Fragmentation of the hemiaminal releases formaldehyde and the unmethylated lysine residue. (B) Proposed mechanism for JmjC-catalyzed arginine demethylation, a reaction which is analogous to lysine demethylation. JmjC, JumonjiC; KDM, lysine-specific histone demethylase; RDM, arginine-specific histone demethylase.

role in histone modification, and have important functions in epigenetic processes, gene expression and plant development (70). In Arabidopsis spp., two JmjC domain-containing proteins, JMJ20 and JMJ22, function as histone arginine demethylases on H4R3 that act as positive regulators of seed germination in the phytochrome B-phytochrome interacting factor 3-like 5-somnus pathway (71,72).

Nevertheless, JMJD6 was considered display two distinct functions, arginine demethylase and lysyl-hydroxylase (73). Webby et al (73) reported that arginine-rich (RS) domains synthesized with dimethylated arginine residues could be Jmjd6 substrates, such as U2AF65 and LUC7-like2 (LUC7L2). Using mass spectrometry analyses, this study did not observe dimethyl arginine-demethylation in U2AF65 or LUC7L2, nor in histones. Rather, it was detected that the hydroxylation of U2AF65 was significantly increased with JMJD6 overexpression. Combined with the essential role of JMJD6 in mRNA splicing, it was confirmed that JMJD6 catalyzed the lysyl hydroxylation of U2AF65, serving a specific role in the regulation of RNA splicing (73). Previously, Heim et al (74) reported that JMJD6 interacts with the RS-domains of specific SR-like proteins and is involved in RNA-protein complexes, which has an effect on the splicing of reporter genes. Therefore, there is a degree of doubt regarding whether JMJD6 contains a focal role in demethylation arginine enzyme activity (75). Further studies should also clarify whether there are other enzymes that function as specific arginine demethylases on histones and non-histones.
Mechanisms of action and perspectives on JmjC histone lysine demethylases. A subset of $\mathrm{Fe}$ (II)- and 2OG-dependent JmjC containing oxygenases, histone lysine demethylases, has been reported to be able to catalyze arginine demethylation $(76,77)$. Studies have indicated that arginine and lysine demethylation have similar mechanisms including oxidation of the arginine methyl group, whose reaction is analogous to that of lysine demethylation as described in Fig. 4. Therefore, the Fe (II)- and 2OG oxygenases may represent good candidates arginine methylases. Notably, a previous study revealed that JmjC KDMs are able to catalyze oxidation reactions, which is required for the oxidation of a methylarginine group (78). This research inspired further work into the additional function of KDMs in arginine demethylation.

To test whether the catalytic domains of the JmjC KDMs are able to act as arginine-specific histone demethylases (RDMs), recombinant proteins containing the six identified human JmjC KDM subfamilies [KDM2A, KDM3A, KDM4E, KDM5C, KDM6B and PHF8 (also known as KDM7B0)] were produced (79-81). Demethylation activity was tested with matrix assisted laser desorption ionization-time of flight mass spectrometry. It was observed that KDM3A, KDM4E, KDM5C and KDM6B exhibited demethylation catalytic activity. In addition, KDM4E and KDM5C were demonstrated to catalyze the demethylation of histone peptides methylated at H3R2, H3R8, H3R26 (KDM4E, but not KDM5C) and H4R3, and also certain non-histone peptide sequences. Moreover, 
Table III. JmjC KDMs catalyzing arginine demethylation.

\begin{tabular}{|c|c|c|c|c|c|c|}
\hline Type & Subtype & Hydroxylase & KDM & RDM & Novel RDM & Unknown \\
\hline \multirow[t]{2}{*}{ KDM2 } & KDM2A & - & + & - & - & - \\
\hline & KDM2B & - & + & - & - & - \\
\hline \multirow[t]{3}{*}{ KDM3 } & KDM3A & - & + & - & + & - \\
\hline & KDM3B & - & + & - & - & - \\
\hline & KDM3C & - & + & - & - & - \\
\hline \multirow[t]{5}{*}{ KDM4 } & KDM4A & - & + & - & + & - \\
\hline & KDM4B & - & + & - & - & - \\
\hline & KDM4C & - & + & - & - & - \\
\hline & KDM4D & - & + & - & - & - \\
\hline & KDM4E & - & + & - & + & - \\
\hline \multirow[t]{4}{*}{ KDM5 } & KDM5A & - & + & - & - & - \\
\hline & KDM5B & - & + & - & - & - \\
\hline & KDM5C & - & + & - & + & - \\
\hline & KDM5D & - & + & - & - & - \\
\hline \multirow[t]{2}{*}{ KDM6 } & KDM6A & - & + & - & - & - \\
\hline & KDM6B & - & + & - & + & - \\
\hline \multirow[t]{3}{*}{ KDM7 } & PHF2 & - & + & - & - & - \\
\hline & KDM7A & - & + & - & - & - \\
\hline & PHF8/KDM7B & - & + & - & + & - \\
\hline \multirow[t]{9}{*}{ JmjC only } & MINA53 & + & + & - & - & - \\
\hline & NO66 & + & + & - & - & - \\
\hline & JMJD8 & - & - & - & - & + \\
\hline & JMJD6 & + & - & + & - & - \\
\hline & JMJD4 & + & - & - & - & - \\
\hline & $\mathrm{FIH}$ & + & - & - & - & - \\
\hline & JMJD5/KDM8 & - & + & - & - & - \\
\hline & HSPBAP1 & - & - & - & - & + \\
\hline & JMJD7 & - & - & - & - & + \\
\hline
\end{tabular}

Human JmjC oxygenases grouped according to the sequence analysis of their catalytic domains, indicating their assigned/proposed functions and novel functions identified in a previous study (76); certain assignments remain controversial. JmjC, JumonjiC; KDM, lysine-specific histone demethylase; RDM, arginine-specific histone demethylase.

KDM3A was verified to function as a key epigenetic factor for Janus kinase 2-signal transducer and activator of transcription 3 activation in cancer cells (82). Therefore, based on these observations, certain JmjC KDMs do have RDM activity, as described in Table III. Nonetheless, the reaction of JmjC oxygenases that catalyzes arginine demethylation has been detected in vitro (76). Considerable efforts are required to accurately investigate arginine demethylation, in addition to true specific arginine demethylases, with respect to RDM activity in cells.

Examination of arginine demethylation. Given the ability of recombinant JmjC oxygenases to catalyze the demethylation of arginine residues, as reported by Walport et al (76), the authors of the present study were interested to investigate whether certain JmjC enzyme were also able to catalyze arginine demethylation under normal conditions. To isolate the effective component, Hela nuclear extracts was separated by $(\mathrm{NH} 4)_{2} \mathrm{SO}_{4}$ precipitation (83). Based on the proposed mechanism for histone demethylation (Fig. 5, unpublished), the enzymatic reaction conditions that were used to analyze the $\mathrm{Fe}(\mathrm{II})$ and $\alpha-\mathrm{KG}$ dependent dioxygenase family of histone demethylases were adopted. Notably, significant demethylation activity on symmetrical histone 4 methylated arginine 3 was observed at a $30-50 \%(\mathrm{NH} 4)_{2} \mathrm{SO}_{4}$ concentration, but not at $10-30 \%$, suggesting that a degree of arginine demethylase or enzymatic function on arginine demethylation may exist in this component. In order to isolate and identify arginine demethylase, gel electrophoresis and mass spectrometry analysis are required in the future.

\section{Conclusions and future perspectives}

Post-translational modifications are at the core of the field of epigenetics and are involved in the majority of signal transduction, initiating or amplifying dynamic signals. Arginine 

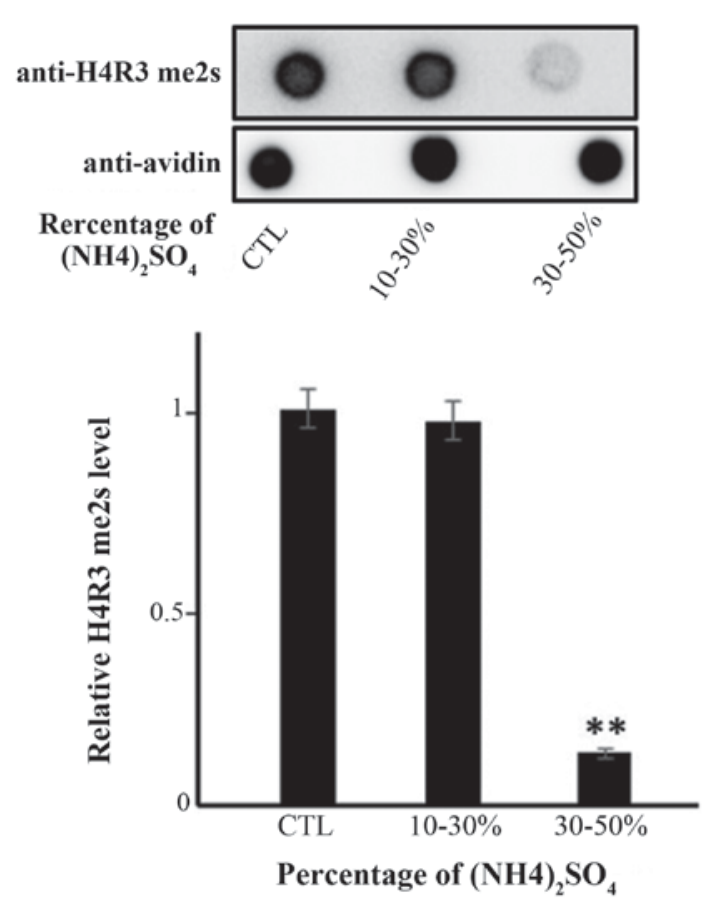

Figure 5. Demethylation activity exists at a $30-50 \%(\mathrm{NH} 4)_{2} \mathrm{SO}_{4}$ precipitation of HeLa nuclear extract. Dot immunoblot analysis of H4R3 me2s following incubation with nuclear extract. Avidin served as a loading control. Western blot analysis represents the results of one experiment, representative of three independent experiments. Student's t-test was performed. ${ }^{* *} \mathrm{P}<0.01$ vs. CTL. CTL, control.

methylation is a key post-translational modification involved in tumorigenesis. Recently, arginine methylation regulation has become a rapidly growing field that carries great promise for extending the understanding of pathological processes. Dysregulation of arginine methylation or the abnormal expression of enzymes responsible for post translational modifications may be key events in numerous diseases, including cancer or other diseases. While it is estimated that arginine methylation is as common as other post translational modifications, only nine PRMTs, but hundreds of kinases and E3 ubiquitin ligases for phosphorylation and ubiquitination, have been reported (84). Despite the research into methylation, it is not possible to conclude that arginine methylation regulation is not as dynamic as other modifications.

Various reports have described the hydroxylation and RDM activities of the JmjC oxygenase JMJD6 $(54,65,73,74)$. Meanwhile, JMJD6 is a molecule of interest for its controversial arginine demethylase activity on histones and other non-histone proteins (75), and a recent study demonstrated that other 2OG-dependent JmjC oxygenase KDMs do have RDM activity (including KDM3A, KDM4E, KDM5C and KDM6B) (76). Studies have demonstrated that certain enzymes extend their functions independently of their own activities. As a histone demethylase, LSD2 was reported to act as an E3 ubiquitin ligase and to inhibit cancer cell proliferation through a histone demethylase-independent pathway (85). Therefore, a hypothesis may be drawn as to whether true specific arginine demethylases exist, or whether other enzymes perform this function as a 'part-time' job. However, negative results cannot rule out the existence of a potential specific arginine demethylase. For our examination of arginine demethylase, we found there was demethylase activity at a $30-50 \%(\mathrm{NH} 4)_{2} \mathrm{SO}_{4}$ concentration of nuclear extracts. Therefore, a novel method required to identify novel enzymes that solely demethylate methylarginines and to understand the dynamic nature of histone demethylases. Finally, the identification and characterization of histone demethylase enzymes may improve the understanding of arginine methylation, and open a new frontier in the study of dynamic epigenetic regulation. Furthermore, molecular investigations in addition to physiological analyses are required to gain a better understanding of the association between the dysregulation of arginine methylation and cancer biology.

\section{Acknowledgements}

Not applicable.

\section{Funding}

The present study was supported by the National Natural Science Foundation (grant no. 31701179), the Program for New Century Excellent Talents in University of Ministry of Education of China (grant no. NCET-13-0868) and the China Postdoctoral Science Foundation (grant no. 2016M591877).

\section{Availability of data and materials}

Not applicable.

\section{Authors' contributions}

$\mathrm{JZ}$ contributed to the literature retrieval, experiments and manuscript preparation. LJ and MHL contributed to the cell culture and sample treatment in addition to manuscript modification. LFH and ZGG supervised the present study, assessed experiment data and contributed to the approval of the final version of the manuscript.

\section{Ethics approval and consent to participate}

Not applicable.

\section{Patient consent for publication}

Not applicable.

\section{Competing interests}

The authors declare that they have no competing interests.

\section{References}

1. Bedford MT and Richard S: Arginine methylation an emerging regulator of protein function. Mol Cell 18: 263-272, 2005

2. Rothbart SB and Strahl BD: Interpreting the language of histone and DNA modifications. Biochim Biophys Acta 1839: 627-643, 2014.

3. Boisvert FM, Chénard CA and Richard S: Protein interfaces in signaling regulated by arginine methylation. Sci STKE 2005: re2, 2005.

4. Yang Y, Lu Y, Espejo A, Wu J, Xu W, Liang S and Bedford MT: TDRD3 is an effector molecule for arginine-methylated histone marks. Mol Cell 40: 1016-1023, 2010. 
5. Gao Y, Zhao Y, Zhang J, Lu Y, Liu X, Geng P, Huang B, Zhang Y and Lu J: The dual function of PRMT1 in modulating epithelial-mesenchymal transition and cellular senescence in breast cancer cells through regulation of ZEB1. Sci Rep 6: 19874, 2016.

6. Pal S, Baiocchi RA, Byrd JC, Grever MR, Jacob ST and Sif S: Low levels of miR-92b/96 induce PRMT5 translation and H3R8/H4R3 methylation in mantle cell lymphoma. EMBO J 26: 3558-3569, 2007.

7. Karkhanis V, Wang L, Tae S, Hu YJ, Imbalzano AN and Sif S: Protein arginine methyltransferase 7 regulates cellular response to DNA damage by methylating promoter histones $\mathrm{H} 2 \mathrm{~A}$ and $\mathrm{H} 4$ of the polymerase $\delta$ catalytic subunit gene, POLD1. J Biol Chem 287: 29801-29814, 2012.

8. Frietze S, Lupien M, Silver PA and Brown M: CARM1 regulates estrogen-stimulated breast cancer growth through up-regulation of E2F1. Cancer Res 68: 301-306, 2008.

9. Pal S, Vishwanath SN, Erdjument-Bromage H, Tempst P and Sif S: Human SWI/SNF-associated PRMT5 methylates histone H3 arginine 8 and negatively regulates expression of ST7 and NM23 tumor suppressor genes. Mol Cell Biol 24: 9630-9645, 2004.

10. Mosammaparast N and Shi Y: Reversal of histone methylation: Biochemical and molecular mechanisms of histone demethylases. Annu Rev Biochem 79: 155-179, 2010.

11. Bedford MT and Clarke SG: Protein arginine methylation in mammals: Who, what, and why. Mol Cell 33: 1-13, 2009.

12. Gary JD and Clarke S: RNA and protein interactions modulated by protein arginine methylation. Prog Nucleic Acid Res Mol Biol 61: 65-131, 1998

13. Bedford MT: Arginine methylation at a glance. J Cell Sci 120: 4243-4246, 2007.

14. Lee $\mathrm{J}$ and Bedford MT: PABP1 identified as an arginine methyltransferase substrate using high-density protein arrays. EMBO Rep 3: 268-273, 2002.

15. Yu MC: The Role of Protein Arginine Methylation in mRNP Dynamics. Mol Biol Int 2011: 163827-163836, 2011.

16. Nishioka K and Reinberg D: Methods and tips for the purification of human histone methyltransferases. Methods 31: 49-58, 2003.

17. Gonsalvez GB, Tian L, Ospina JK, Boisvert FM, Lamond AI and Matera AG: Two distinct arginine methyltransferases are required for biogenesis of Sm-class ribonucleoproteins. J Cell Biol 178: 733-740, 2007.

18. Wei H, Mundade R, Lange $\mathrm{KC}$ and $\mathrm{Lu} \mathrm{T}$ : Protein arginine methylation of non-histone proteins and its role in diseases. Cell Cycle 13: 32-41, 2014

19. Tsai WC, Gayatri S, Reineke LC, Sbardella G, Bedford MT and Lloyd RE: Arginine Demethylation of G3BP1 Promotes Stress Granule Assembly. J Biol Chem 291: 22671-22685, 2016.

20. Shen EC, Henry MF, Weiss VH, Valentini SR, Silver PA and Lee MS: Arginine methylation facilitates the nuclear export of hnRNP proteins. Genes Dev 12: 679-691, 1998.

21. Goulet I, Gauvin G, Boisvenue S and Côté J: Alternative splicing yields protein arginine methyltransferase 1 isoforms with distinct activity, substrate specificity, and subcellular localization. J Biol Chem 282: 33009-33021, 2007

22. Zou L, Zhang H, Du C, Liu X, Zhu S, Zhang W, Li Z, Gao C, Zhao X, Mei M, et al: Correlation of SRSF1 and PRMT1 expression with clinical status of pediatric acute lymphoblastic leukemia. J Hematol Oncol 5: 42, 2012.

23. Elakoum R, Gauchotte G, Oussalah A, Wissler MP Clément-Duchêne C, Vignaud JM, Guéant JL and Namour F: CARM1 and PRMT1 are dysregulated in lung cancer without hierarchical features. Biochimie 97: 210-218, 2014.

24. Shia WJ, Okumura AJ, Yan M, Sarkeshik A, Lo MC, Matsuura S, Komeno Y,Zhao X, Nimer SD, Yates JR III, et al: PRMT1 interacts with AML1-ETO to promote its transcriptional activation and progenitor cell proliferative potential. Blood 119: 4953-4962, 2012.

25. Mathioudaki K, Papadokostopoulou A, Scorilas A, Xynopoulos D, Agnanti N and Talieri M: The PRMT1 gene expression pattern in colon cancer. Br J Cancer 99: 2094-2099, 2008.

26. Mathioudaki K, Scorilas A, Ardavanis A, Lymberi P, Tsiambas E, Devetzi M, Apostolaki A and Talieri M: Clinical evaluation of PRMT1 gene expression in breast cancer. Tumour Biol 32: 575-582, 2011

27. Mathioudakis $\mathrm{N}$ and Salvatori R: Adult-onset growth hormone deficiency: Causes, complications and treatment options. Curr Opin Endocrinol Diabetes Obes 15: 352-358, 2008.

28. Papadokostopoulou A, Mathioudaki K, Scorilas A, Xynopoulos D, Ardavanis A, Kouroumalis E and Talieri M: Colon cancer and protein arginine methyltransferase 1 gene expression. Anticancer Res 29: 1361-1366, 2009.
29. Zhong J, Cao RX, Zu XY, Hong T, Yang J, Liu L, Xiao XH, Ding WJ, Zhao Q, Liu JH, et al: Identification and characterization of novel spliced variants of PRMT2 in breast carcinoma. FEBS J 279: 316-335, 2012

30. Zhong J, Cao RX, Hong T, Yang J, Zu XY, Xiao XH, Liu JH and Wen GB: Identification and expression analysis of a novel transcript of the human PRMT2 gene resulted from alternative polyadenylation in breast cancer. Gene 487: 1-9, 2011.

31. Takahashi Y, Iwai M, Kawai T, Arakawa A, Ito $\mathrm{T}$, Sakurai-Yageta M, Ito A, Goto A, Saito M, Kasumi F, et al: Aberrant expression of tumor suppressors CADM1 and 4.1B in invasive lesions of primary breast cancer. Breast Cancer 19: 242-252, 2012

32. Singh V, Miranda TB, Jiang W, Frankel A, Roemer ME, Robb VA, Gutmann DH, Herschman HR, Clarke S and Newsham IF: DAL-1/4.1B tumor suppressor interacts with protein arginine N-methyltransferase 3 (PRMT3) and inhibits its ability to methylate substrates in vitro and in vivo. Oncogene 23 7761-7771, 2004

33. Hong H, Kao C, Jeng MH, Eble JN, Koch MO, Gardner TA Zhang S, Li L, Pan CX, Hu Z, et al: Aberrant expression of CARM1, a transcriptional coactivator of androgen receptor, in the development of prostate carcinoma and androgen-independent status. Cancer 101: 83-89, 2004.

34. Majumder S, Liu Y, Ford OH III, Mohler JL and Whang YE Involvement of arginine methyltransferase CARM1 in androgen receptor function and prostate cancer cell viability. Prostate 66: 1292-1301, 2006

35. Kim YR, Lee BK, Park RY, Nguyen NT, Bae JA, Kwon DD and Jung C: Differential CARM1 expression in prostate and colorectal cancers. BMC Cancer 10: 197, 2010.

36. Habashy HO, Rakha EA, Ellis IO and Powe DG: The oestrogen receptor coactivator CARM1 has an oncogenic effect and is associated with poor prognosis in breast cancer. Breast Cancer Res Treat 140: 307-316, 2013

37. Wang L, Pal S and Sif S: Protein arginine methyltransferase 5 suppresses the transcription of the RB family of tumor suppressors in leukemia and lymphoma cells. Mol Cell Biol 28: 6262-6277, 2008

38. Bao X, Zhao S, Liu T, Liu Y, Liu Y and Yang X: Overexpression of PRMT5 promotes tumor cell growth and is associated with poor disease prognosis in epithelial ovarian cancer. $\mathrm{J}$ Histochem Cytochem 61: 206-217, 2013

39. Powers MA, Fay MM, Factor RE, Welm AL and Ullman KS: Protein arginine methyltransferase 5 accelerates tumor growth by arginine methylation of the tumor suppressor programmed cell death 4. Cancer Res 71: 5579-5587, 2011.

40. Yoshimatsu M, Toyokawa G, Hayami S, Unoki M, Tsunoda T, Field HI, Kelly JD, Neal DE, Maehara Y, Ponder BA, et al: Dysregulation of PRMT1 and PRMT6, Type I arginine methyltransferases, is involved in various types of human cancers. Int J Cancer 128: 562-573, 2011.

41. Thomassen M, Tan Q and Kruse TA: Gene expression meta-analysis identifies chromosomal regions and candidate genes involved in breast cancer metastasis. Breast Cancer Res Treat 113: 239-249, 2009.

42. Yao R, Jiang H, Ma Y, Wang L, Wang L, Du J, Hou P, Gao Y, Zhao L, Wang G, et al: PRMT7 induces epithelial-to-mesenchymal transition and promotes metastasis in breast cancer. Cancer Res 74: 5656-5667, 2014

43. Baldwin RM, Haghandish N, Daneshmand M, Amin S, Paris G, Falls TJ, Bell JC, Islam S and Côté J: Protein arginine methyltransferase 7 promotes breast cancer cell invasion through the induction of MMP9 expression. Oncotarget 6: 3013-3032, 2015.

44. Yang Y and Bedford MT: Protein arginine methyltransferases and cancer. Nat Rev Cancer 13: 37-50, 2013.

45. Tee WW, Pardo M, Theunissen TW, Yu L, Choudhary JS, Hajkova P and Surani MA: Prmt5 is essential for early mouse development and acts in the cytoplasm to maintain ES cell pluripotency. Genes Dev 24: 2772-2777, 2010.

46. Pawlak MR, Scherer CA, Chen J, Roshon MJ and Ruley HE: Arginine N-methyltransferase 1 is required for early postimplantation mouse development, but cells deficient in the enzyme are viable. Mol Cell Biol 20: 4859-4869, 2000.

47. Yu Z, Chen T, Hébert J, Li E and Richard S: A mouse PRMT1 null allele defines an essential role for arginine methylation in genome maintenance and cell proliferation. Mol Cell Biol 29: 2982-2996, 2009

48. Blanc RS and Richard S: Arginine Methylation: The Coming of Age. Mol Cell 65: 8-24, 2017. 
49. Shi Y, Lan F, Matson C, Mulligan P, Whetstine JR, Cole PA, Casero RA and Shi Y: Histone demethylation mediated by the nuclear amine oxidase homolog LSD1. Cell 119: 941-953, 2004.

50. Tsukada Y, Fang J, Erdjument-Bromage H, Warren ME, Borchers $\mathrm{CH}$, Tempst $\mathrm{P}$ and Zhang Y: Histone demethylation by a family of JmjC domain-containing proteins. Nature 439: 811-816, 2006.

51. Lee DY, Teyssier C, Strahl BD and Stallcup MR: Role of protein methylation in regulation of transcription. Endocr Rev 26: 147-170, 2005

52. Wysocka J, Allis CD and Coonrod S: Histone arginine methylation and its dynamic regulation. Front Biosci 11: 344-355, 2006.

53. Ng SS, Yue WW, Oppermann U and Klose RJ: Dynamic protein methylation in chromatin biology. Cell Mol Life Sci 66: 407-422, 2009.

54. Chang B, Chen Y, Zhao Y and Bruick RK: JMJD6 is a histone arginine demethylase. Science 318: 444-447, 2007.

55. Li S, Ali S, Duan X, Liu S, Du J, Liu C, Dai H, Zhou M, Zhou L, Yang L, et al: JMJD1B Demethylates H4R3me2s and H3K9me2 to Facilitate Gene Expression for Development of Hematopoietic Stem and Progenitor Cells. Cell Rep 23: 389-403, 2018.

56. Hino S, Kohrogi K and Nakao M: Histone demethylase LSD1 controls the phenotypic plasticity of cancer cells. Cancer Sci 107: $1187-1192,2016$.

57. Shen HJ, Xu WQ and Lan F: Histone lysine demethylases in mammalian embryonic development. Exp Mol Med 49: e325, 2017.

58. Vossenaar ER, Zendman AJ, van Venrooij WJ and Pruijn GJ PAD, a growing family of citrullinating enzymes: Genes, features and involvement in disease. BioEssays 25: 1106-1118, 2003.

59. Nakashima K, Hagiwara T and Yamada M: Nuclear localization of peptidylarginine deiminase $\mathrm{V}$ and histone deimination in granulocytes. J Biol Chem 277: 49562-49568, 2002.

60. Hagiwara T, Nakashima K, Hirano H, Senshu T and Yamada M: Deimination of arginine residues in nucleophosmin/B23 and histones in HL-60 granulocytes. Biochem Biophys Res Commun 290: 979-983, 2002.

61. Holbert MA and Marmorstein R: Structure and activity of enzymes that remove histone modifications. Curr Opin Struct Biol 15: 673-680, 2005.

62. Cuthbert GL, Daujat S, Snowden AW, Erdjument-Bromage H, Hagiwara T, Yamada M, Schneider R, Gregory PD, Tempst P, Bannister AJ, et al: Histone deimination antagonizes arginine methylation. Cell 118: 545-553, 2004.

63. Wang Y, Wysocka J, Sayegh J, Lee YH, Perlin JR, Leonelli L, Sonbuchner LS, McDonald CH, Cook RG, Dou Y, et al: Human PAD4 regulates histone arginine methylation levels via demethylimination. Science 306: 279-283, 2004.

64. Fadok VA, Bratton DL, Rose DM, Pearson A, Ezekewitz RA and Henson PM: A receptor for phosphatidylserine-specific clearance of apoptotic cells. Nature 405: 85-90, 2000.

65. Poulard C, Rambaud J, Hussein N, Corbo L and Le Romancer M: JMJD6 regulates ER $\alpha$ methylation on arginine. PLoS One 9: e87982, 2014.

66. Poulard C, Rambaud J, Lavergne E, Jacquemetton J, Renoir JM, Trédan O, Chabaud S, Treilleux I, Corbo L and Le Romancer M: Role of JMJD6 in Breast Tumourigenesis. PLoS One 10: e0126181, 2015.

67. Lawrence P, Conderino JS and Rieder E: Redistribution of demethylated RNA helicase A during foot-and-mouth disease virus infection: Role of Jumonji C-domain containing protein 6 in RHA demethylation. Virology 452-453: 1-11, 2014.

68. Gao WW, Xiao RQ, Peng BL, Xu HT, Shen HF, Huang MF, Shi TT, Yi J, Zhang WJ, Wu XN, et al: Arginine methylation of HSP70 regulates retinoid acid-mediated RAR $\beta 2$ gene activation. Proc Natl Acad Sci USA 112: 3327-3336, 2015.

69. Tsai WC, Reineke LC, Jain A, Jung SY and Lloyd RE: Histone arginine demethylase JMJD6 is linked to stress granule assembly through demethylation of the stress granule-nucleating protein G3BP1. J Biol Chem 292: 18886-18896, 2017.
70. Noh B, Lee SH, Kim HJ, Yi G, Shin EA, Lee M, Jung KJ, Doyle MR, Amasino RM and Noh YS: Divergent roles of a pair of homologous jumonji/zinc-finger-class transcription factor proteins in the regulation of Arabidopsis flowering time. Plant Cell 16: 2601-2613,2004

71. Chen X, Hu Y and Zhou DX: Epigenetic gene regulation by plant Jumonji group of histone demethylase. Biochim Biophys Acta 1809: 421-426, 2011.

72. Cho JN, Ryu JY, Jeong YM, Park J, Song JJ, Amasino RM, Noh B and Noh YS: Control of seed germination by light-induced histone arginine demethylation activity. Dev Cell 22: 736-748, 2012.

73. Webby CJ, Wolf A, Gromak N, Dreger M, Kramer H, Kessler B, Nielsen ML, Schmitz C, Butler DS, Yates JR III, et al: Jmjd6 catalyses lysyl-hydroxylation of U2AF65, a protein associated with RNA splicing. Science 325: 90-93, 2009.

74. Heim A, Grimm C, Müller U, Häußler S, Mackeen MM, Merl J, Hauck SM, Kessler BM, Schofield CJ, Wolf A, et al: Jumonji domain containing protein 6 (Jmjd6) modulates splicing and specifically interacts with arginine-serine-rich (RS) domains of SR- and SR-like proteins. Nucleic Acids Res 42: 7833-7850, 2014.

75. Böttger A, Islam MS, Chowdhury R, Schofield CJ and Wolf A: The oxygenase Jmjd6--a case study in conflicting assignments. Biochem J 468: 191-202, 2015.

76. Walport LJ, Hopkinson RJ, Chowdhury R, Schiller R, Ge W, Kawamura A and Schofield CJ: Arginine demethylation is catalysed by a subset of JmjC histone lysine demethylases. Nat Commun 7: 11974, 2016.

77. Markolovic S, Wilkins SEand SchofieldCJ: Protein Hydroxylation Catalyzed by 2-Oxoglutarate-dependent Oxygenases. J Biol Chem 290: 20712-20722, 2015.

78. Hopkinson RJ, Walport LJ, Münzel M, Rose NR, Smart TJ, Kawamura A, Claridge TD and Schofield CJ: Is JmjC oxygenase catalysis limited to demethylation? Angew Chem Int Ed Engl 52: 7709-7713, 2013

79. Williams ST, Walport LJ, Hopkinson RJ, Madden SK, Chowdhury R, Schofield CJ and Kawamura A: Studies on the catalytic domains of multiple JmjC oxygenases using peptide substrates. Epigenetics 9: 1596-1603, 2014.

80. Klose RJ, Kallin EM and Zhang Y: JmjC-domain-containing proteins and histone demethylation. Nat Rev Genet 7: 715-727, 2006.

81. Klose RJ, Gardner KE, Liang G, Erdjument-Bromage H, Tempst $\mathrm{P}$ and Zhang Y: Demethylation of histone H3K36 and H3K9 by Rph1: A vestige of an $\mathrm{H} 3 \mathrm{~K} 9$ methylation system in Saccharomyces cerevisiae? Mol Cell Biol 27: 3951-3961, 2007.

82. Kim H, Kim D, Choi SA, Kim CR, Oh SK, Pyo KE, Kim J, Lee SH, Yoon JB, Zhang Y, et al: KDM3A histone demethylase functions as an essential factor for activation of JAK2-STAT3 signaling pathway. Proc Natl Acad Sci USA 115: 11766-11771, 2018.

83. Tsukada Y and Zhang Y: Purification of histone demethylases from HeLa cells. Methods 40: 318-326, 2006.

84. Larsen SC, Sylvestersen KB, Mund A, Lyon D, Mullari M, Madsen MV, Daniel JA, Jensen LJ and Nielsen ML: Proteome-wide analysis of arginine monomethylation reveals widespread occurrence in human cells. Sci Signal 9: rs9, 2016.

85. Yang Y, Yin X, Yang $\mathrm{H}$ and $\mathrm{Xu}$ Y: Histone demethylase LSD2 acts as an E3 ubiquitin ligase and inhibits cancer cell growth through promoting proteasomal degradation of OGT. Mol Cell 58: 47-59, 2015.

This work is licensed under a Creative Commons Attribution-NonCommercial-NoDerivatives 4.0 International (CC BY-NC-ND 4.0) License. 